\title{
PUBLIC INTEREST ISSUES IN THE GLOBAL INFORMATION SOCIETY: IS THERE A ROLE FOR PUBLIC AUTHORITIES?
}

\author{
Vassilios Laopodis ${ }^{1}$ \\ European Commission, DG III-Industry, Brussels
}

\begin{abstract}
The development of the Global Information Society (GIS) and in particular electronic commerce is characterized by three major phenomena:

- $\quad$ the generalized globalization of the world economy;

- $\quad$ the widening deregulation of economic sectors, notably of telecommunications;

- $\quad$ the convergence of IT, telecommunications, broadcasting and publishing.

These mutually reinforcing phenomena are driven by a common cause - the rapid pace of technological developments, most notably in data processing and signal transmission.
\end{abstract}

In the networked global economy, regional and national perceptions of the GIS - of the advantages it affords and the menaces it brings - can be widely divergent. However, despite this, as demonstrated by the numerous multi-lateral (WTO, OECD, WIPO, etc.) and bi-lateral agreements and declarations between governments alone (EU-US, US-Japan, EU-Japan, $A P E C)$ and with industry (TABD, EU-Japan round table, etc.), it is widely held that the private sector should lead the way toward the Global Information Society, with only 'light' regulations guiding us where necessary along the way.

Ordinary citizens hear of the dawn of a new era that is ushering in momentous changes that will permanently alter the way we buy products and services, interact with public authorities, access information and spend leisure time. Can we be sure that the end-beneficiaries of new technologies are keeping pace with change? Can we be sure that their legitimate interests are fully accounted for in the offerings of the GIS?

The intent of this paper is not to analyse the merits or potential difficulties of living in the society being shaped by new technologies, but to investigate how the private sector may lead the way toward the GIS and how attention to the 'public interest' may be a guiding principle in the process. Furthermore the paper attempts to bring answers to questions such as: is there a role left to other actors in this process, notably the end-users, whether they be private citizens or businesses, large or small, and in particular the public authorities?

In examining these issues, the paper first discusses the concept of 'public interest' and the socio-economic implications of the phenomenon and then presents the position of the various actors as they have been formulated in the many documents and declarations issued by 
governments, industry and consumer associations. Finally it comments national initiatives from individual countries/regions.

\section{PROTECTING PUBLIC INTEREST: WHAT, WHY AND HOW?}

With the emergence of the GIS, an increasingly large proportion of economic transactions is being shifted from the physical world to the on-line realm, which is largely free of physical obstacles to interaction and transaction. In these conditions, entirely new services are developing and thriving. Electronic commerce, which is the first widespread business application to take advantage of new technologies, is fundamentally changing the way business is conducted (Micossi 1998).

The Internet is a global medium that knows no national boundaries. Presently there exist approximately 100 countries allowing for Internet access and 20 million Internet hosts worldwide, of which over 5 million are in Europe where a further 6 million are forecast to be added over the next 5 years (www.nw.com). It is difficult to calculate the number of actual Internet users, but it is currently estimated to be in the region of 100 million (see www.nua.ie/surveys).

It is forecast that this figure will increase to a quarter of a billion users by the year 2000 (www.gip.org). Today there are more than 200000 of Internet Web sites with 11 million pages of data, pictures, sound and text from none in 1991 and about 100 in 1992 (see fig. 1 below).

Recent growth in Internet use is largely attributed to the introduction of the graphical and user-friendly World Wide Web (WWW). The Web did not exist in 1991. In 1992, it comprised 100 sites. Today there are more than 200000 of them, with 11 million pages of data, pictures, sound and text.

Electronic commerce definitions may differ and estimates may vary, but nevertheless there are clear indications of a strong growth. Estimates published in July 1997 (www.forrester.com) indicated that business-tobusiness commerce over the Internet will reach 7 billion ECU in 1997 - a tenfold increase from 1996. In 2002, it is forecast that the value of goods and services traded between companies over the Internet will approach 300 billion ECU (www.gip.org). 
Internet Hosts

(Thousands)

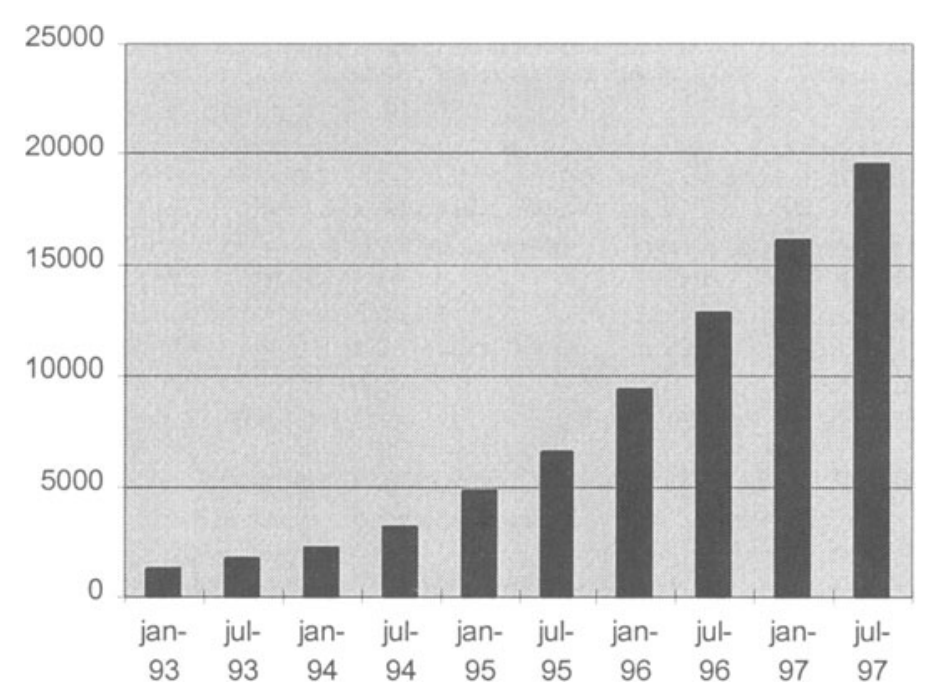

Fig 1. Evolution of Internet hosts (Source: Network Wizards)

The issue of serving the public interest - and thus the general interest has always been at the forefront of policy-makers' concerns. The Community concept of European Society is adding further substance to this issue by actively promoting and protecting the public interest.

In this context one should first identify, what are the interests that must be preserved for the public in order to allow this? This question must be answered if public authorities and market actors are to know what obligations they must meet. Furthermore, determining what constitutes a public interest is of paramount importance and will allow assessing whether today's notion of public interest remains valid in the context of an evolving communication and media environment and of an increasingly networked global economy. Some argue that the concept of public interest must evolve with the times; still others assert that the public's basic interests remain valid and that only the ways in which they are satisfied may evolve. In either case, a proper assessment requires a clear outline of the underlying objectives (EC 1997a). 
Among the many issues of importance in this discussion, the following items, in our view, could be considered as the most relevant public interest issues.

\subsection{Universal service}

Universal service refers to the basic right of a citizen to have access to specific services. In the case of the GIS, it is generally held that the public has the right to today's basic means of communication, namely fixed telephone service and certain television and radio broadcasts. Traditionally, the public service mission fell on certain telecommunications operators and broadcasters. If providing the service proved to be an unfair burden for them, the cost could be shared amongst other market players. However, with the convergence of IT, telecommunications, broadcasting and publishing, the burden of providing basic public services could be shared more equitably between operators. Thus, a review of the current costsharing system is in order (EC 1997b).

\subsection{Content control}

Measures for controlling content have been applied to the broadcast and print media for many years. It is generally accepted that, even in free societies, regulators should exercise some degree of control in order to protect the public from any harmful or illegal content to which they have free access, especially when an operator who has a public service mission broadcasts the content. The issue, as concerns content control, is not over the validity of particular rules but whether the means of achieving public interest objectives should be reviewed in light of the impact of technology on particular services. For example, the strict content rules applied to freeto-air broadcasts would be too stringent if applied to pay-TV, given the specific characteristics of the latter. Several approaches have been proposed internationally such as the WIPO treaties of December 1996 on Copyright, and on Performances and Phonograms, the Commission's proposal for a draft directive on copyright and related rights in the Information Society (EC 1997c). This directive will complement the existing Community framework on copyright and related rights, which addresses already certain copyright issues related to the Information Society. 


\subsection{Public service broadcasting}

Broadcasters entrusted with a public service mission must reappraise their role in the convergent environment. Their relative market share gradually diminishes as the public is faced with an increasingly vast choice of audiovisual choices. At the same time, regulators must constantly assess the extent to which public service objectives are met by normal market activity, including the new media, and whether the regulations to be met by broadcasters may be lightened.

\subsection{Privacy and data protection}

The end-users of new services must be assured of the security of information transmitted over networks. Legislation has already been agreed at the Community level (EC 1995) and this will soon be complemented by specific rules governing data protection and privacy in telecommunications (EC 1997d). Data protection is also being tackled by the Council of Europe (1981 Convention on Data Protection).

\subsection{Cryptography and digital signatures}

Related to the need to assure privacy is the requirement to allow entirely secure data transmission and transactions over networks. The European Commission has already issued a Communication on this matter, which recommends a number of measures aimed at ensuring security and trust in electronic communications (EC 1997e). Electronic commerce is global and, thus, requires that cryptographic products be internationally available and that they correspond to the real needs of business and individuals. OECD agreed on 'Guidelines for Cryptography Policy' in 1997 and high tech crime was discussed at the G8 Summit in Denver (1997) and at the ministerial meeting in Boston in December 1997.

\subsection{Cultural diversity and multilingualism}

The European Community recognises that cultural policy objectives can equate to public interest objectives, a position embodied in a landmark case brought before the European Court of Justice which involved the media 
sector Traditionally, the public service broadcasters have been the preferred vehicle for pursuing such objectives.

\subsection{Protection of minors and public order}

The difficulty of exercising controls on potentially harmful content on the Internet provides another example of how convergence is challenging traditional regulatory approaches to implementing controls. Given the global nature of the platform, the solutions that are emerging draw on selfregulatory practices by industry and on technologies that give parents greater responsibility and control.

One could in addition consider that other most specific issues related to Internet and in particular electronic commerce should also belong into this category, e.g. duties and tariffs over the Internet, Internet governance, liability, applicable law, Intellectual Property Rights, digital signatures, taxation. These items, together with the issues of security, data protection/privacy, and illegal and harmful content, constitute the points of the agenda proposed by the Commission in February 1998 in its Communication on 'Globalisation and Information Society: the need for strengthened international cooperation' (EC 1998). In this important document the Commission proposes the establishment of an International Charter which will take the form of a political declaration at global level by both private sector/industry and governments worldwide. For this purpose a broad consultation has started at the initiative of the European Commission.

\section{GENERAL PUBLIC INTEREST ISSUES}

In discussions about public interest issues, some fundamental social, ethical and economic consequences of convergence and of the globalisation of the world economy are often neglected. In our view three other objectives must be pursued alongside those outlined above, namely:

- avoiding adverse socio-economic consequences;

- taking consumer interests into account;

- reaching international co-operation for consensus.

It is generally accepted that the GIS permeates current thinking on future economic development and will have a societal impact equivalent in 
magnitude to that of the industrial revolution a century ago. In studying these implications, one should consider the new services and activities from the perspective of end-users (consumers, workers, and citizens). It is important, for example, to determine how comfortable end-users are with using new technologies and services. Their confidence in new technologies, which will determine their willingness to use them, will be enhanced through the development of the appropriate regulatory framework.

There are different sensitivities around the world to these concerns. Europe clearly takes the lead as demonstrated by its ceaseless effort to address all relevant issues in its Communications, green papers and other official texts (EC 1996, 1997a).

\subsection{Socio-economic changes}

The most evident socio-economic changes brought about by convergence result specifically from the emergence of electronic commerce, which is a worldwide phenomenon. In the context of an increasingly networked world economy, enhanced economic and industrial competitiveness has two prerequisites (Misocci 1998).

- The creation of support services which inspire trust in all parties involved electronic commerce and which cover all stages of the transaction chain, from design and production, through marketing logistics and delivery.

- The adoption by business of electronic commerce technologies and methods with an aim to improving quality, building new relationships with suppliers and entering new markets.

Electronic commerce must not be viewed as a single industrial sector, but rather as a facilitating infrastructure that covers every conceivable sector of the economy. From this perspective, electronic commerce is clearly a horizontal issue, which may provoke structural changes in all industrial sectors and thus revitalise declining industries and regions. Generally, the employment situation in countries stands to benefit from the advent of electronic commerce as large companies reorient themselves toward newly accessible markets. There are examples, however, of certain sectors, such as banking, that will be negatively impacted by electronic commerce. In such cases, due emphasis must be placed on re-training employees in order to provide them with the mixture of skills required by the new employment 
market. Re-training is equally important in the overall learning and teaching process, as well as in the reorientation of RTD activities.

The effects on employment were in the agenda of the special Summit of the European Union in Luxembourg in 1997, and several reports study the phenomenon and propose different approaches to remedy to these problems 2,3 .

Finally, the emergence of the global market place has given rise to a need for international cooperation to reach wide consensus on those critical issues that risk stifling the development of electronic commerce, as well as to reach agreement on the appropriate level of regulation to be applied by the private sector and, in particular, by governments in defence of the public interest.

\subsection{Public sector's different roles}

Another interesting dimension of public sector involvement in the promotion of information society is its role as major user of ICT products and services and as provider of services to the public through electronic means (certificates, information, bills, tax payments etc.).

Public administration deals with large numbers of functionally distributed organisations. Electronic Commerce present an innovative opportunity to overcome problems and re-organise its services and processes in order to improve the internal effectiveness and the interaction between different levels and functions within public administrations (Themistocleous et al 1998). So, to succeed in providing efficient and effective public services the government should take a number of measures such as:

- re-organise the business processes of public administration;

- archive and warehouse the information collected by public administrations;

- unify information models to enable sharing of information between different levels and functions of public administrations.

This affects the quality of public service provision, which focuses in the simplification, the automation, and the integration of all transactions performed between public services and citizens (including individuals, enterprises, tourists, etc.). 
The other areas of interest concern the mass and accurate information to the citizens and on-line democracy, and the integration of services and applications of all relevant services and applications in the public sector as well as integration with services of non-public actors [Themistocleous et al 1998, Laopodis et al 1998).

Finally, the Ethics dimension is very often under-evaluated in the discussion. International discussion in Learned Societies such as International Federation of Information processing IFIP 9.2 SIG and others are reflecting on these issues (Berleur et al 1997, Berleur \& Whitehouse 1997).

\section{RESPECTIVE ROLES}

An analysis of the different positions worldwide indicates that there is in principle a basic consensus on the respective roles of private sector, consumers, users and governments. However there still exist fundamental differences between regions in particular regarding data protection where Europe believes that regulation is needed, encryption where US and some European countries would like to have a strict control for defence reasons.

\subsection{The private sector}

The private sector has clearly outlined its vision of the GIS, a vision, which is widely shared by the major industrialised countries, although with varying degrees of consent within Europe and throughout the world. This vision rests upon four basic principles (TABD 1997, Laopodis 1997):

- the GIS shall be industry-led and market-driven;

- the most appropriate regulation is self-imposed by industry;

- governments must avoid applying excessive regulations; interoperable solutions shall be implemented using voluntary, open industry standards. 


\subsection{Consumers}

Consumer reflection regarding new technologies is based on the fundamental 'Consumer Principles' such as: access, choice, safety, information, equity, redress, and representation. Consumers are concerned that important decisions that will have direct impact on them are being made without their input. In Europe, where they are represented at the Community level by the ANEC (European Association for the co-ordination of consumer representation in standardisation) in issues related to standardisation and new technologies, consumers have outlined their vision which identifies a series of requirements as addressed to the European standardisation system (CEN, CENELEC, ETSI through the Information and Communications Technologies Standards Board-ICTSB). This list of requirements comprise the following critical points 4,5 .

Ease of use, design for all, functionality of solution, multi-cultural and multi-lingual aspects, terminology, comprehensive standards, consistent user interface, adaptability, provision of system status operation, exportability, privacy and security of information, cost transparency, quality of service, system reliability and durability, reliability of information, health and safety issues, environmental issues, rating and grading systems.

With respect to public interest as seen by public authorities the following issues attain a particular attention:

Security and Privacy: Consumers would like to have guarantees of the reliability, authenticity and integrity of information obtained on-line. To this end, they require public encryption systems and a legally regulated security infrastructure. Finally, consumers want access to the sort of information that will empower them.

Interoperability and Compatibility: Consumers want products to be produced according to the concept of 'designed to last'. Indeed, the rapid pace of technological advancements should not render existing products obsolete before the consumer is reasonable satisfied of having made a 'return' on investment; whether the return is evaluated in terms of increased productivity, convenience, pleasure of ownership, etc.

Designed for All: Consumers are concerned that products be designed to be accessible to all. They want applications and services that avoid social exclusion by taking into consideration the special needs of, for example, the elderly and disabled.

Cultural Diversity: Consumers have expressed their desire to see cultural diversity preserved in the GIS. One means of achieving this objective is to 
reserve a place for all languages; no single language should dominate communications and oblige everyone to adopt it in order to reap the full benefits offered by the GIS.

Control of Illegal and Harmful Content: Consumers would like to see prevailing standards of decency revisited.

\subsection{Governments}

In addition to protecting the public interest, public authorities have another important task in the development of the GIS, that of eliminating barriers to the free circulation of information, services and products. In this pursuit, two key policy objectives must be reached. First, a clear and predictable legal and regulatory framework must be put in place. This step creates favourable conditions for business investment. Second, governments have a role to play in initiating new services in the critical areas of education, training, healthcare and the environment.

Around the world, governments have taken steps to facilitate the transition to the new global marketplace. Bilateral agreements have been reached and joint declarations have been made by the major world players (EU, US, Japan, Canada, APEC, etc.). Conferences, at which critical topics are addressed, have brought together all relevant parties, i.e. industry, government, international standardisation bodies and represen-tatives of all conceivable end-users.

Apart the Commissions Communication on European initiative in Electronic Commerce (EC 1997f), several countries have already developed policy frameworks to face the emerging need for solutions, regulatory or not. For example the French government has just published a comprehensive report on electronic commerce 6 , the German Federal Ministry of Economics published its initiative of the Federal government comprising 11 major action lines 7 , and in 1996 the Netherlands published their strategy document: Knowledge in action 8 and the UK a discussion paper on Government Electronic Business-The opportunity, UKFWG9. Outside Europe, in 1997 the following major initiatives took place: the US Framework for global electronic commerce ${ }^{10}$, Japan's 'Towards the age of digital economy' 11 , Canada's 'Preparing Canada for a digital world' 12 . In addition European countries including those from CEECs agreed on the socalled Bonn Declarations ${ }^{13}$ from governments, industry and consumers. 


\section{CONCLUSION}

A consensus is emerging on some of the most critical issues regarding protection of public interest. The basic points on which all parties agree are as follows:

- Governments will not regulate for the sake of regulation. Emphasis will be placed on industry self-regulation, with governments intervening to ensure the provision of basic services and promote healthy competition in the marketplace.

- All regulation must meet legitimate general interest objectives effectively and efficiently. In Europe, regulation must adhere to the principles of the Single Market.

Furthermore, governments have a role to play in ensuring privacy, security, and protection for IPRs and conditional access services, as well as to apply a clear and neutral tax regime to services. In this respect they have invited the private sector to provide with self-regulation solutions concerning the above issues. In an absence of response or unacceptable delays by industry, governments, at least in Europe, are ready to legislate in order to protect public interest and create a favourable business environment for electronic commerce and deployment of the information society.

\section{NOTES}

1 The views expressed in this paper (presented in August 1998) are personal and do not necessarily reflect the official positions of the European Commission

2 The impact of the development of electronic commerce on the employment situation in European commerce (Athens Un. Of Economics and Business on behalf of EuroFIET and EuroCommerce), March 1998.

3 ACTS/fair programme : New dimension of social exclusion in a Telematic society.

4 Association of European Consumers in Standardisation (ANEC) Consumer Protection report

5 ANEC-Consumer requirements in relation to standardisation, ANEC 1997/ICT/012, April 1997.

6 Lorentz report : Commerce Electronique : une nouvelle donneee pour les consommateurs, les entreprises, les citoyens et les pouvoir publics http://www.finances.gouv.fr/commerce-electroinique/lorentz/som_detaile.htm

7 Electronic Commerce: Initiative of the Federal Government, Bonn 1997.

8 NL : Strategy document : Knowledge in action, Min. of Econ. affairs, NL, June, 1996. 
9 UK : Government Electronic Business-The opportunity, UKFWG, discussion paper, 1996.

10 US : A Framework for global electronic commerce, White House, Washington, December 10, 1997.

11 Japan : Towards the age of digital economy, MITI, Japan, April 1997.

12 Canada : Preparing Canada for a digital world, Final report of the IIAC, Canada, September 1997.

13 Bonn Ministerial Conference, July 1997.

\section{REFERENCES}

Berleur, J., Whitehouse, D. and Brunnstein, K. (eds.) (1997) Ethics of Computing. Chapman and Hall, London.

Berleur, J. and Whitehouse, D. (eds.) (1997) An ethical global information society: culture and democracy revisited. Proceedings of IFIP 9.2 Corfu conference, Corfu Greece May 1997. Chapman and Hall, London.

EC (1995) Directive on the protection of individuals with regard to the processing of personal data and on the free movement of such data (Directive 95/46/EC).

EC (1996) Information Society Forum : Networks for people and their Communities. Report to the EC, Brussels, June 1996.

EC (1997a) The social and labour market dimension of the Information Society: People First - The Next Steps. High Level Group of Experts on the Social aspects COM(97) 390.

EC (1997b) Green Paper on the convergence of the Telecommunications, Media and Information Technology sectors, and the implications for regulation. European Commission $\operatorname{COM}(97) 623$, Brussels 26.11.97; http://www.ispo.cec.be/convergencegp

EC (1997c) Commission's proposal for a draft directive on copyright and related rights in the Information Society (COM(97)628fin).

EC (1997d) Directive concerning the processing of personal data and the protection of privacy in the telecommunications sector (Directive 97/66/EC).

EC (1997e) Commission Communication Towards a European Framework for Digital Signatures and Encryption. COM(97) 503, October 1997.

EC (1997f) European initiative in Electronic Commerce, EC April 1997.

EC (1998) Communication of the Commission 'Globalisation and Information Society: the need for strengthened international cooperation'. COM 98(50) final.

http://www.ispo.cec.be/eif/policy/com9850en.html 
Laopodis, V. (ed.) (1997) Global Standards Conference. 1-3 October 1997, http://www.ispo.cec.be/standards/conf97

Laopodis, V., Berger, W., Boulle, C., Arzano, F. and Devictor, B. (1998) Public sector, global networks and industry self-regulation. Proc. EuroMed Net'98 conference, Cyprus, 4-7 March 1998.

Micossi S. (1998) Creating a favourable business environment for electronic commerce : the role of European industrial policy. EC DG III, January 1998.

TABD (1997) Rome Communique, November 1997.

Themistocleous, M., Poulimenakou, A., Laopodis, V. and Doukidis, G. (1998) Public sector and Electronic Commerce. Proc. Bled '98 Conference, Bled, Slovenia (to appear). 